\begin{tabular}{|l|l|r|}
\hline & Al Fitrah & Relevansi Dongeng Dengan \\
\hline Journal Of Early Childhood Islamic Education & Pembentukan Karakter AUD \\
\hline ISSN : 2599-2287 E-ISSN : 2622-335X & Eliya NS. Husnul.B, \\
& Fol.2 No.2 Januari 2019 & Fatrima SS \\
\hline
\end{tabular}

\title{
RELEVANSI DONGENG DENGAN PEMBENTUKAN KARAKTER ANAK USIA DINI
}

\begin{abstract}
Abstrak
Pembentukan karakter pada anak usia dini bukan hanya menjadi tanggung jawab guru, tetapi juga tanggung jawab orangtua dan masyarakat lainnya. Sangat penting memahami perkembangan karakter anak sejak usia dini. Usiadini merupakan masa pertumbuhan dan perkembangan yang sangat menentukan perkembangan masa selanjutnya Permasalahan yang diangkat dalam penelitian ini adalah Relevansi dongeng dengan pembentukan karakter anak usia dini. Tujuan penelitian ini adalah untuk mengetahui Relevansi dongeng dengan pembentukan karakter anak usia dini.Dalam penelitian ini penulis menggunakan (library tesearch), yaitu; penelitian teks/naskah, penelitian materi bahasa dan sastra, dan penelitianpenelitian suatu korpus yang sumbernya dari bahan-bahan pustaka. Dalam menjawab masalah ini, peneliti mengumpulkan data dengan menyusun atau mengklarifikasi, dan menganalisanya, teknik pengumpulan data mengadakan studi penelaan terhadap buku-buku, literatur-literatur, catatancatatan, dan laporan-laporan yang ada hubunganya dengan masalah yang dipecahkan. Hasil penelitian menyimpulkan bahwa dongeng merupakan metude yang sangat bagus untuk pembentukan karakter anak usia dini karena dangan dongeng anak akan lebih capat memahami pesan moral dan karakter apa yang ingin di sampaikan melalui dongeng tersebut . Oleh karena itu pembentukan karakter perlu dibentuk dan dibina sejak usia dini. Ada puncara pengembangan karakter yaitu melalui pola pengasuhan dari lingkungan keluarga, sekolah, dan peran ligkungan masyarakat.
\end{abstract}

\section{Kata kunci: Relevansi, Dongeng, pembentukan karakter}

\begin{tabular}{|r} 
Eliya Nopita Sari $^{1}$ \\
Husnul Bahri \\
${ }^{2}$ \\
Fatrima Santri Syafri $^{3}$ \\
${ }^{1}$ eliya.nopitasari@gmail.com \\
${ }^{3}$ husnulbahri_Syukur@yahoo.com \\
fatrimasantrisyafri@iainbengkulu.ac.id \\
IAIN Bengkulu
\end{tabular}

dilihat, didengar, dirasakan, mereka seolaholah tak pernah berhenti bereksplorasi dan belajar. Anak usia dini adalah sosok individu yang sedang menjalani suatu proses perkembangan dengan pesat dan fundamental bagi kehidupan selanjutnya. Anak usia dini berada pada rentang usia 0-8 


\begin{tabular}{|l|l|r|}
\hline A1 Fitrah & Relevansi Dongeng Dengan \\
Journal Of Early Childhood Islamic Education & Pembentukan Karakter AUD \\
ISSN $:$ 2599-2287 E-ISSN $:$ 2622-335X & Eliya NS. Husnul.B, \\
Vol.2 No.2 Januari 2019 & Fatrima SS \\
\hline
\end{tabular}

tahun pada masa ini proses pertumbuhan dan perkembangan dalam berbagai aspek sedang mengalami masa yang cepat dalam rentang perkembangan hidup manusia ${ }^{1}$.

Berdasarkan Undang-undang

Nomor 20 Tahun 2003 tentang sistem pendidikan Nasional berkaitan dengan pendidikan Anak Usia Dini tertulis pada pasal 28 ayat 1 yang berbunyi pendidikan Anak Usia Dini diselenggarakan bagi anak sejak lahir sampai dangan enam tahun dan bukan merupakan prasyarat untuk mengikuti pendidikan dasar. Selanjutnya pada Bab 1 pasal 1 ayat 14 ditegaskan bahwa pendidikan anak usia dini adalah suatu upaya pembinaan yang ditujukan kepada anak sejak lahir sampai dangan usia enam tahun yang dilakukan melalui pemberian rangsangan pendidikan untuk membantu pertumbuhan dan perkembangan jasmani dan rohani agar anak memiliki kesiapan dalam memasuki pendidikan lebih lanjut.

Masa usia dini merupakan masa paling penting untuk sepanjang kehidupannya, sebab masa usia dini adalah masa pembentukan pondasi dan dasar kepribadian yang akan menentukan pengalaman selanjutnya. Banyak para ahli yang menilai bahwa periode 5 tahun sejak kelahiran akan menentukan perkembangan selanjutnya. $^{2}$

Pendidikan anak usia dini pada hakikatnya adalah pendidikan yang diselenggarakan dengan tujuan untuk memfasilitasi pertumbuhan dan

1 . Yuliani Nurani Sujiono konsep dasar pendidikan anak usia dini, (jakarta:PT Indeks,2014) hal 6

2. Novan Ardy Wiyani, Konsep Dasar PAUD ,(Yogyakarta: Gava Media, 2016) Hlm 8 perkembangan anak secara menyeluruh atau menekankan pada pengembangan seluruh aspek keperibadian anak. ${ }^{3}$

Pendidikan masa awal kanak-kanak ditantang untuk memperkenalkan anakanak kepada dunia untuk masa depan mereka, suatu dunia yang akan terus meningkat menjadi multikultural dan banyak suku. Metode dongeng adalah salah satu alat yang kuat untuk meningkatkan suatu pemahaman diri dan orang lain.

Dongeng merupakan bentuk sastra lama yang bercerita tentang suatu kejadian yang luar biasa yang penuh khayalan yang dianggap oleh masyarakat suatu hal yang tidak benar-benar terjadi ${ }^{4}$. Dongeng menurut kamus besar bahasa indonesia adalah cerita yang tidak benar-benar terjadi terutama tentang kejadian zaman dulu yang aneh-aneh. $^{5}$ Lebih lanjut Isbell, juga menegaskan mendongeng mempunyai banyak kegunaan didalam pendidikan utama anak. Dia menyimpulkan bahwa dongeng menyediakan suatu kerangka konseptual untuk berpikir, yang menyebabkan anak dapat membentuk pengalaman menjadi keseluruhan yang dapat mereka pahami. Dongeng menyebabkan anak-anak dapat menetapkan secara mental pengalaman dan melihat gambaran di dalam kepala mendongengkan dongeng tradisional menyediakan anakanak suatu model bahasa dan pikiran bahwa mereka dapat meniru Nur Ahyani. Kekuatan utama dari strategi dongeng

3 . Suyadi. Teori pembelajaran anak usia dini,(Bandung,PT Remaja Rosdakarya) Hlm22

${ }^{4}$ Winda B. Nungtjik, Mendongeng untuk anak usia dini, ( Tanggerang Selatan: Aksara pustaka endukasi, 2016) Hlm 37

5 . Abdullah,Spd, Kamus basar bahasa indonesia, hal 274 


\begin{tabular}{|l|l|r|}
\hline & Al Fitrah & Relevansi Dongeng Dengan \\
Journal Of Early Childhood Islamic Education & Pembentukan Karakter AUD \\
ISSN : 2599-2287 E-ISSN : 2622-335X & Eliya NS. Husnul.B, \\
Vol.2 No.2 Januari 2019 & Fatrima SS \\
\hline
\end{tabular}

adalah menghubungkan rangsangan melalui penggambaran karakter. Dongeng memiliki potensi untuk memperkuat imajinasi, memanusiakan individu, meningkatkan empati dan pemahaman,memperkuat nilai dan etika, serta merangsang proses pemikiran kritis dan kreatif. Mendongeng dapat dijadikan sebagai media pembentukan karakter pada anak usia dini. Dengan mendongeng akan memberikan pengalaman belajar bagi anak usia dini.

Metode mendongeng dapat memberikan sejumlah pengalaman yang dibutuhkan dalam perkembangan kejiwaan anak. Dengan dongeng akan memberikan wadah bagi anak untuk belajar berbagai emosi dan perasaan serta belajar nilai-nilai karakter. Anak akan belajar pada pengalaman-pengalaman sang tokoh dalam dongeng, setelah itu memilah mana yang dapat dijadikan panutan olehnya sehingga membentuknya menjadi sebuah karakter yang baik.

Karakter merupakan keadaan asli yang ada dalam diri individu seseorang yang membedakan antara dirinya dengan orang lain. Karakter juga merupakan perilaku manusia yang berhubungan dengan Tuhan Yang Maha Esa, diri sendiri, sesama manusia, lingkungan, dan kebangsaan yang terhujud dalam pikiran, sikap, perasaan, perkataan, dan perbuatan berdasarkan norma-norma agama, hukum, tata krama, budaya, dan adat istiadat ${ }^{6}$.

Berdasarkan kondisi seperti tersebut di atas peneliti mencoba memakai Metode mendongeng sebelum tidur untuk

6. Heri Gunawan, pendidikan karakter kondep dan implementasi, (Bandung: Alfabeta, 2017) hlm 3 membentuk karakter pada anak. Hal ini bertujuan supaya anak tidak bosan dan lebih tertarik dalam pembelajaran. Penelitian ini dilakukan dengan tujuan untuk mengetahui relevansi atau hubungan pembentukan karakter dangan metode berdongeng sebelum tidur. Peneliti berharap melalui mendongeng sebelum tidur di dalam keluarga anak menjadi lebih tertarik dan antusias dalam belajar sehingga anak melaksanakan kegiatan dengan sukarela dan hati senang sehingga kegiatan belajar berjalan dengan lancar dan tujuan pembelajaran bisa tercapai.

Maka penulis mengambil judul: "RELEVANSI DONGENG DENGAN PEMBENTUKAN KARAKTER ANAK USIA DINI".

\section{Kajian Teori \\ Pengertian Dongeng}

Hakikat dongeng adalah berkomunikasi. Mengomunikasikan sebuah cerita tentang hal-hal yang menghibur untuk anak-anak. Karena itu bagi anak-anak mendongeng adalah debuah hiburan. Dongeng adalah dunia dalam kata. Kehidupan yang dituliskan dengan kata-kata. Dunia yang berisi cerita yang menakjubkan mengenai dunia binatang, kerajaan, benda-banda, bahkan roh-roh, dan raksasa ${ }^{7}$.

Mendongeng adalah seni tertua warisan leluhur yang saat ini sudah mulai dilupakan oleh sebagian besar masyarakat padahal kegiatan mendongeng sangat perlu dilestarikan dan dikembangkan sebagaisalah satu sarana positif guna

\footnotetext{
7. Heru Kurniawan, keajaiban mendongeng,
} ( Jakarta: PT Bhuana Ilmu Populer, 2013) hlm 71 


\begin{tabular}{|l|l|r|}
\hline A1 Fitrah & Relevansi Dongeng Dengan \\
Journal Of Early Childhood Islamic Education & Pembentukan Karakter AUD \\
ISSN $:$ 2599-2287 E-ISSN $:$ 2622-335X & Eliya NS. Husnul.B, \\
Vol.2 No.2 Januari 2019 & Fatrima SS \\
\hline
\end{tabular}

mendukung berbagai kepentingan sosial secara luas. Jauh sebelum munculnya peninggalan tertulis maupun buku, manusia berkomunikasi dan merekam peristiwaperistiwa kehidupa mereka secara bertutur turun temurun.Tradisi lisan dahulu sempat menjadi primadona dan andalan para orang tua, terutama ibu dan nenek dalam mengantar tidur anak atau cucu mereka.

Berdasarkan pengertian-pengertian tersebut, maka dapat disimpulkan bahwa dongeng adalah cerita fiktif yang bertujuan untuk menghibur dan mengandung nilainilai budi pekerti di dalamnya. Kegiatan mendongeng atau berceita adalah suatu media komunikasi yang ampuh dalam mentransfer ide dan gagasan kapada anak dalam sebuah kemasan menarik. Mendongeng merupakan cara terbaik bagi orangtua untuk mengkomunikasikan pesanpesan cerita yang mengandung unsur etika, moral, maupun nilai-nilai agama ${ }^{8}$.

\section{Pengertiaan karakter}

Sebelum dijelaskan pengertian dari pendidikan karakter akan diuraikan terlebih dahulu makna karakter, baik secara etimologi maupun terminologi. Melalui penajaman karakter tersebut akan dapat diketahui pengertian pendidikan karakter

Secara etimologis, kata karakter berasal dari bahasa latin kharakter atau bahasa yunani kharassein yang berarti memberi tanda (to mark), atau bahasa prancis carakter, yang berarti membuat tajam atau membuat dalam (Majid dan Andayani). Dalam bahasa inggris character, memiliki arti watak, karakter, sifat, peran

${ }^{8}$ Agoes Dariyo, Psikologi Perkembangan anak tiga tahun pertama, ( Jakarta: PT Refika Aditama, 2011) hlm 161 dan huruf (Echol dan Shadiliy). Dalam kamus umum Bahasa indonesia, karakter diartikan sebagai tabiat, watak, sifat-sifat kejiwaan, akhlak, atau budi pekerti yang membedakan seseorang dari pada yang lain (Poerwadarmint).

Sedangkan secara terminologis, para ahli mendefinisikan karakter dengan redaksi yang berbeda-beda. Endang Sumantri menyatakan, karakter ialah suatu kualitas positif yang dimiliki seseorang, sehingga membuat menarik dan atraktif; seseorang yang unusual atau memiliki kepribadian eksentrik.

\section{Pengertian Anak Usia Dini}

Anak usia dini menurut National Association for the Edication Young Childen menyatakan bahwa anak usia dini merupakan anak yang berada pada usia nol sampai dengan delapan tahun.Usia dini merupakan masa perkembangan dan pertumbuhan yang sangat menentukan perkembangan masa selanjutnya. Berbagi studi yang dilakukan para ahli menyimpulkan bahwa pendidkan anak sejak usia dini dapat memperbaiki prestasi dan meningkatkan produktivitas kerja masa dewasanya ${ }^{9}$.

Pendidikan anak usia dini adalah suatu upaya pembinaan yang ditujukan kepada anak sejak lahir sampai dengan usia enam tahun yang dilakukan melalui pembinaan rangsangan pendidikan untuk membantu pertumbuhan dan perkembangan jasmani dan rohani agar anak memiliki kesiapan dalam memasuki pendidikan lebih lanjut.

9 .Ahmad Susanto, Pendidikan Anak Usia Dini, (Jakarta : PT Bumi Aksara, 2017) hlm 1 


\begin{tabular}{|l|l|r|}
\hline & Al Fitrah & Relevansi Dongeng Dengan \\
Journal Of Early Childhood Islamic Education & Pembentukan Karakter AUD \\
ISSN : 2599-2287 E-ISSN $: 2622-335 X$ & Eliya NS. Husnul.B, \\
Vol.2 No.2 Januari 2019 & Fatrima SS \\
\hline
\end{tabular}

PAUD sebagai pendidikan yang yang diselenggarakan sebelum jenjang pendidikan dasar, memiliki kelompok sasaran anak usia 0-6 tahun yang disebut sebagai masa emas perkembangan. Di samping itu, pada usia ini anak-anak, masih sangat rentan yang apabila penangannya tidak tepat justru dapat merugikan anak itu sendiri. Oleh karena itu, penyelenggaraan PAUD harus memperhatikan dan sesuai dengan tahap-tahap perkembangan anak. Program PAUD tidak dimaksudkan untuk mencuri start apa-apa yang seharusnya diperoleh pada jenjang pendidkan dasar, melainkan untuk memberikan fasilitasi pendidikan yang sesuai bagi anak, agar anak pada saatnya memiliki kesiapan baik secara fisik, mental, maupun sosial/emosionalnya dalam rangka memasuki pendidkan lebih lanjut.

Peranan orang tua dan pendidik pada dasarnya mengarahkan anak-anak sebagai generasi unggulan, karane potensi anak tidak akan tumbuh dengan sendirinya tampak banruan orang tua ${ }^{10}$

\section{Metode Penelitian}

Penelitian ini menggunakan metode deskriptif kualitatif yaitu metode yang digunakan untuk meneliti suatu objek yang berisi informasi faktual yang menggambarkan sagala sesuatu tentang keterangan waktu, statistik, fakta-fakta mengenai perstiwa historis dan juga peristiwa fikiran.

Penelitian ini termasuk kedalam penelitian kepustakaan (library

research) oleh karena itu data yang diteliti

10.Ahmad Susanto, perkembangan anak usia dini, (jakarta: kencana prenada media group, 2012) hal 2 berupa naskah-naskah atau buku-buku yang bersumber dari kepustakaan untuk itu, data yang akan diambil sepenuhnya berasal dari kepustakaan atau buku-buku. ${ }^{11}$

\section{Pembahasan}

\section{Hubungan dongeng dengan pembentukan karakter anak usia dini}

Dongeng merupakan cerita yang tidak benar-benar terjadi yang berisi tentang petualangan yang penuh imajinasi, kadang tidak masuk akal dengan menampilkan situasi dan para tokoh yang luar biasa, bersifat huburan dan terdapat ajaran moral yang terkandong dalam dongeng tersebut. Adapun nilai-nilai moral doneng individual meliputi (1) kepatuhan, (2) keberanian, (3) rela berkorban, (4) jujur, (5) adil dan bijaksana, (6) menghormati dan menghargai, (7) bekerja keras, (8) menepati janji, (9) tahu balas budi, (10) rendah hati, dan (12) hati- hati dalam bertindak.

Nilai-nilai moral sosial meliputi (1) bekerjasama, (2) suka menolong, (3) kasih sayang, (4) kerukunan, (5) suka memberi nasihat, (6) peduli nasib orang lain, dan (7) suka mendoakan orang lain. Sementara itu, nilai-nilai moral religi meliputi (1) percaya kekuasaan Tuhan, (2) percaya adanya Tuhan, (3) berserah diri kepada Tuhan atau bertawakal, dan (4) memohon ampun kepada Tuhan.

Karakter adalah serangkaian tabiat, kepribadian, akhlak, budi pekerti, personalitas, perilaku, perasaan, dan pemikiran dalam diri individu manusia sebagai ciri khas pembeda dirinya dengan

11 Mustika Zed, metode penelitian kepustakaan (jakarta; yayasan obor Indonesia,2017) hal 3 


\begin{tabular}{|l|l|r|}
\hline A1 Fitrah & Relevansi Dongeng Dengan \\
Journal Of Early Childhood Islamic Education & Pembentukan Karakter AUD \\
ISSN $:$ 2599-2287 E-ISSN $:$ 2622-335X & Eliya NS. Husnul.B, \\
Vol.2 No.2 Januari 2019 & Fatrima SS \\
\hline
\end{tabular}

orang lain yang menjadi kebiasaan dan menimbulkan

perbuatan-perbuatan (kebaikan) tanpa adanya dorongan serta dilakukan secara terus-menerus dalam lingkup pengembangan meliputi nilai-nilai keagamaan dan moral, fisik, kognitif, bahasa, seni, dan sosial-emosional. karakter-karakter yang menjadi pilar yang harus ditanamkan kepada siswa atau peserta didik mencakup sepuluh karakter utama antara lain; (1) dapat dipercaya (trusswhortiness); (2) rasa hormat dan perhatian (respect); (3) tanggung jawab (responsiblity); (4) jujur (fairness); (5) peduli (caring); (6) kewarganegaraan (citizenship); (7) ketulusan (honesty); (8) berani (courage); (9) tekun (deligence) (10) integritas (integrity). ${ }^{12}$

Adapun salah satu metode yang dapat digunakan dalam pendidikan karakter yaitu Metode berceita atau mendongeng (Telling Story) Metode ini pada hakikatnya sama dengan metode ceramah. Tetapi guru atau orang tua lebuh leluasa berimprovisasi, misalnya melalui perubahan mimik, gerak tubuh, mengubah intonasi suara seperti keadaan yang hendak dilukiskan dan sebagainya. Guru atau orang tua harus bisa memilih cerita atau dongeng yang memiliki hikmah yang baik untuk anak-anak.

Guru atau orang tau bisa mengambil hikmah dari cerita keberhasilan para tokoh perjuangan, para tokoh ternama, dan para pesohor yang berjuang mati-matian sebelum mencapai keberhasilan. Esensi cerita oleh guru berupa biografi singkat para tokoh atau pesohor, orang-orang

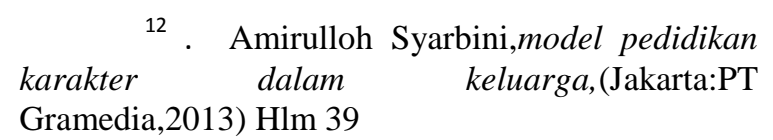

yangg berhasil tersebut. Pada umumnya mereka berangkat dari bawah dengan pejuangan yang penuh semangat, berkarakter tidak kenal putus asa, atau pantang menyerah. Gigih dan tangguh, cerdas memaknai kehidupan, tidak berhenti belajar dengan kegairahan yang tinggi, jujur terhadap diri sendiri dan orang lain, serta peduli kepada orang yang menderita memerlukan bantuan. Atau dapan juga guru bercerita tentang bagaimana kasih sayang seorang ibu membuat anan-anak mereka menjadi orang besar ${ }^{13}$.

Anak usia dini adalah anak usia 0-6 tahun dengan pertumbuhan dan perkembangan yang sangat pesat dengan daya serap otaknya yang cepat. Anak usia dini merupakan usia yang tepat bagi orang tua dan pendidik dalam menanamkan nilai-nilai karakter psitif.

Di lihat dari pengertian dongeng dan karakter serta nilai-nilai yang terdapat dalam dongeng dan karakter-karakter yang menjadi pilar yang harus ditanamkan kepada siswa serta metode yang dapat di gunakan dalam pendidikan karakter maka hubungan antara dongeng dengan pembentukan karakter sangat erat, karena salah satu cara pembentukan karakter untuk anak usia dini adalah dengan cara mendongeng, karena dongeng merupakan hal yang menyenangkan bagi anak usia dini, dalam dongeng juga terdapat nilai moral yang dapat membentuk karakter anak, seperti nilai kejujuran, disipli, mandiri, toleransi dan rasa ingin tahu.

\section{Membentuk karakter anak dengan dongeng}

13. Muchlas Samani dan Hariyanto, Konsep dan model pendidikan karakter,(Bandung:PT Remaja Rosdakarya,2011) Hlm 148 


\begin{tabular}{|l|l|r|}
\hline & Al Fitrah & Relevansi Dongeng Dengan \\
Journal Of Early Childhood Islamic Education & Pembentukan Karakter AUD \\
ISSN $: 2599-2287$ E-ISSN $:$ 2622-335X & Eliya NS. Husnul.B, \\
& Fol.2 No.2 Januari 2019 & Fatrima SS \\
\hline
\end{tabular}

Cara atau metode mendididk anak yang mudah adalah dengan bercerita. Sebagaian besar anak senak dengan cerita, baik cerita sesungguhnya maupun dekedar dongeng fiksi belaka. Ketika anak ditawarkan untuk dibacakan cerita atau mendengarkan suatu kisah maka anak akan diam dan menunggu cerita itu.

Melalui dongeng atau cerita, daya imajinasi anak akan berkembang. Anak akan dibawa ke dunia lain yang begitu bebas, luas. Alur cerita dapat dibuat sedemikian rupa sehingga pengalaman baru yang hanya tampil dalam bayangan seakan dapat merika wujudkan dalam kenyataan. Dongeng anak mudah mereka ingat dari pada hafalan mata pelajaran tertentu. Hidayati menjelaskan bahwa mendongeng atau bercerita merupakan salah satu strategi dalam pembelajaran di sekolah, khususnya pada tingkat pendidikan dasar. Tidak hanya di sekolah, mendongeng juga menjadi alternatif cara belajar yang bisa diterapkan di luar sekolah, yaitu di rumah atau keluarga. Melalui dongeng, orang tua, kakek, nenek, atau anggota keluarga lainnya dapat menyampaikan pesan moral kepada putra-putrinya atau cucunya.

Pembentukan karakter melalui dongeng di sekolah dapat dilakukan dengan berbagai cara, diantaranya melalui cara-cara berikut ini: (1) mewajibkan siswa untuk membaca dongeng sekali setiap minggu yang disediakan perpustakaan sekolah; (2) guru membacakan dongeng yang menarik di depan kelas seminggu sekali, (3) lima menit sebelum pelajaran dimulai, siswa membaca dongeng yang disukainya; (4) siswa mencatat nilai-nilai moral dari dongeng yang telah dibaca; (5) guru menugasi siswa membuat rigkasan mengenai dongeng yang dibacanya seminggu sekali; dan (6) membuat kliping dongeng dari majalah atau koran semiggu sekali.

Pendidikan karaker juga dapat ditanamkan di luar sekolah, misalnya di lingkungan keluarga. Cara yang dapat dilakukan adalah (1) orangtua atau saudara membacakan dongeng sebelum tidur atau di waktu luang; (2) di rumah disediakan bacaaan-bacaan dongeng sehingga bisa menarik minat anak untuk membaca; (3) orangtua mengajukan pertanyaan kepada anak untuk melihat pemahaman dan ingatan anak tentang isi dongeng; dan (4) orangtua mengajak anak ke toko buku dan memberikan kesempatan pada anak untuk membeli buku yang disukainya, termasuk dongeng.

Manfaat lain dari dongeng adalah menjadi sarana efektif untuk menyampaikan pesan moral dan menanamkan nilai kebaikan. Tanpa disuruh anak dengan sendirinya menyerap nilainilai moral yang diajarkan oleh sebuah dongeng hingga membekas dalam sanubarinya. Nilai-nilai moral yang disampaikan melalui dongeng jauh lebih efektif dan bermakna dibandingkan dengan ceramah biasa.

\section{Kesimpulan}

Berdasarkan analisis data yang telah peneliti lakukan, maka dapat menyimpulkan, Dongeng merupakan cerita yang tidak benar-benar terjadi yang berisi tentang petualangan yang penuh imajinasi, kadang tidak masuk akal dengan menampilkan situasi dan para tokoh yang 


\begin{tabular}{|l|l|r|}
\hline A1 Fitrah & Relevansi Dongeng Dengan \\
Journal Of Early Childhood Islamic Education & Pembentukan Karakter AUD \\
ISSN $:$ 2599-2287 E-ISSN $:$ 2622-335X & Eliya NS. Husnul.B, \\
Vol.2 No.2 Januari 2019 & Fatrima SS \\
\hline
\end{tabular}

luar biasa, bersifat huburan dan terdapat ajaran moral yang terkandong dalam dongeng tersebut.

Karakter adalah serangkaian tabiat, kepribadian, akhlak, budi pekerti, personalitas, perilaku, perasaan, dan pemikiran dalam diri individu manusia sebagai ciri khas pembeda dirinya dengan orang lain yang menjadi kebiasaan dan menimbulkan perbuatan-perbuatan (kebaikan) tanpa adanya dorongan serta dilakukan secara terus-menerus dalam lingkup pengembangan meliputi nilai-nilai keagamaan dan moral, fisik, kognitif, bahasa, seni, dan sosial-emosional.

Pembentukan karakter anak tidak hanya dilakukan dalam pembelajaran di sekolah, tetapi juga dapat dilakukan di lingkungan rumah atau keluarga. Strategi pembentukan karakter yang dapat dilakukan di sekolah adalah siswa wajib membaca dongeng yang ada di perpustakaan sekolah sekali setiap minggu; guru membacakan dongeng di depan kelas seminggu sekali. Pembentukan karakter dalam lingkungan keluarga dapat dilakukan dengan cara orangtua atau saudara membacakan dongeng sebelum tidur atau di waktu luang; menyediakan bacaan-bacaan dongeng di rumah untuk menarik minat baca anak; orangtua mengajukan pertanyaan kepada anak untuk melihat pemahaman dan ingatan anak tentang isi dongeng.

\section{DAFTAR PUSTAKA}

Abdullah,Spd, Kamus basar bahasa indonesia, hal 274

Agoes Dariyo, Psikologi Perkembangan anak tiga tahun pertama, ( Jakarta: PT Refika Aditama, 2011) hlm 161

Ahmad Susanto, Pendidikan Anak Usia Dini, (Jakarta : PT Bumi Aksara, 2017) hlm 1

Ahmad Susanto, perkembangan anak usia dini, (jakarta: kencana prenada media group, 2012) hal 2

Amirulloh Syarbini,model pedidikan karakter dalam keluarga,(Jakarta:PT Gramedia,2013) Hlm 39

Heri Gunawan, pendidikan karakter kondep dan implementasi, (Bandung: Alfabeta, 2017) hlm 3

Heru Kurniawan, keajaiban mendongeng, ( Jakarta: PT Bhuana Ilmu Populer, 2013) hlm 71

Muchlas Samani dan Hariyanto, Konsep dan model pendidikan karakter,(Bandung:PT Remaja Rosdakarya,2011) Hlm 148

Mustika Zed, metode penelitian kepustakaan (jakarta; yayasan obor Indonesia,2017) hal 3

Novan Ardy Wiyani, Konsep Dasar PAUD ,(Yogyakarta: Gava Media, 2016) HIm 8

Suyadi. Teori pembelajaran anak usia dini,(Bandung,PT Remaja Rosdakarya) Hlm22

Winda B. Nungtjik, Mendongeng untuk anak usia dini, ( Tanggerang Selatan: 


\begin{tabular}{|l|l|r|}
\hline & Al Fitrah & Relevansi Dongeng Dengan \\
\hline Journal Of Early Childhood Islamic Education & Pembentukan Karakter AUD \\
\hline ISSN : 2599-2287 E-ISSN : 2622-335X & Eliya NS. Husnul.B, \\
& Fol.2 No.2 Januari 2019 & Fatrima SS \\
\hline
\end{tabular}

Aksara pustaka endukasi, 2016) Hlm 37

Yuliani Nurani Sujiono konsep dasar pendidikan anak usia dini, (jakarta:PT Indeks,2014) hal 6 